\title{
The Use of Complementary and Alternative Medicine among Korean Young Adult Members of Fitness Centers
}

\author{
Seung-Nam Kim $\mathbb{D}^{1},{ }^{1}$ Bokmin Kim, ${ }^{2}$ and Jaehee Kim ${ }^{2}{ }^{2}$ \\ ${ }^{1}$ College of Korean Medicine, Dongguk University, Goyang-si, Gyeonggi-do, Republic of Korea \\ ${ }^{2}$ Graduate School of Alternative Medicine, Kyonggi University, Seoul, Republic of Korea \\ Correspondence should be addressed to Jaehee Kim; jk41@kgu.ac.kr
}

Received 23 October 2018; Revised 21 December 2018; Accepted 17 February 2019; Published 24 February 2019

Academic Editor: Keturah R. Faurot

Copyright (c) 2019 Seung-Nam Kim et al. This is an open access article distributed under the Creative Commons Attribution License, which permits unrestricted use, distribution, and reproduction in any medium, provided the original work is properly cited.

\begin{abstract}
In general, the pattern and perception of complementary and alternative medicine (CAM) use in young people are little known. Particularly, given South Korea's dual health care system that includes both Korean traditional medicine and Western medicine, young adults in South Korea may be unique for the study of CAM use. Accordingly, this study investigated the modality, purpose, and perceptions of CAM use among young adults in South Korea and determined the predictors of CAM use. In addition, reasons for CAM use were compared to those for exercise. A survey was conducted among 649 young members of fitness centers (aged $20-$ 39 years). The structured written questionnaire included the questions related to use of 30 CAM modalities, satisfaction with CAM use, factors associated with CAM use, reasons for exercise and CAM use, and perceptions of CAM. The most common therapies used in lifetime were acupuncture, massage, moxibustion/cupping, yoga, and diet-based therapies. The most satisfied therapy was massage followed by aroma therapy. The main reasons for using CAM were to relieve musculoskeletal pains while those for doing exercise were to lose weight, to promote health, and to have a positive body image. Multiple logistic regression analysis revealed that higher education level, having a religion, and having a health problem were significant independent predictors of CAM use after controlling for other factors. The majority of respondents reported "relief of pain and symptoms" as the perceived effect of CAM and "lack of advertising" as the weakness of CAM. The majority of respondents got CAM information from mass media and Internet. In conclusion, CAM use is significantly associated with education level, religious status, and health status in Korean young adult members of fitness centers. The main purposes of utilizing CAM and performing exercise are different.
\end{abstract}

\section{Introduction}

Prevalence of complementary and alternative medicine (CAM) use is different across countries depending on diverse cultural and social backgrounds $[1,2]$. CAM use is associated with several factors such as sex, age, education, and income $[1,3]$. In general, it is well-known that CAM use increases with age [1-3], but few studies have examined CAM use in younger adults: Most of previous studies about CAM use have been focused on users in older age since CAM users tended to be middle-aged or elderly [1,3-5]. Previous studies about CAM use in young people were mostly focused on university students [6-10] and their use of dietary supplements (17\%$65 \%)$.

Unlike most countries, Korean traditional medicine is recognized as a conventional medicine in the national healthcare system of South Korea, but a separated medical system with Western medicine [11]. In addition, the overall reputation of Korean traditional medicine in South Korea has rapidly improved in the 1990s. Therefore, the patterns and perceptions of CAM use in young adults in South Korea may be different from older adults and those in other countries.

Since it is generally not known about the patterns, reasons, and perspectives of CAM use in young adults, we investigated these aspects of CAM use in young adults. Moreover, we also investigated whether reasons for CAM use and exercise are different in young adults, especially among physically active young adults, because CAM and exercise are common nonpharmacological and nonsurgical approaches for health promotion and the relief of diseases and symptoms [12-14]. Generally, young adults are known to engage in exercise more than older ones [14] and exercise 
is associated with other health-related behaviors in young adults [15]. Fitness center members exercised more regularly and were more physically active and less sedentary [16, 17]. Given the similarity of exercise and CAM as preventive health care modalities and the age-related differences in utilization of both modalities, we investigated the prevalence, modalities, predictors, reasons, and the perceived benefits and weaknesses of CAM use among young adult members of fitness centers and determined the factors related to CAM use. In addition, reasons for CAM use were compared to those for exercise.

\section{Methods}

2.1. Study Design. The survey was conducted at 7 local commercial fitness centers in Seoul and Gyeonggido in South Korea in 2016. Ethical approval for this study was obtained from Institutional Review Board of Korea National Institute for Bioethics Policy (IRB approval No. P01-201602-23-002). The IRB approved that the study protocols met the criteria for IRB exemption and did not require individual informed consent. All participation was voluntary and anonymous.

2.2. Study Sample. The survey was conducted among 720 young adults (aged 20-39 years) enrolled in fitness centers at the time of study participation. The majority of respondents were doing aerobic and resistance exercises. Seventy-one subjects with incomplete survey were excluded. A total of 649 young adults completed the survey.

All participants were asked to anonymously and voluntarily complete the structured written questionnaire consisted of a series of closed-ended questions. The questionnaire was administered by a staff member at the fitness center. The members of fitness centers were asked if they would be willing to participate in a survey of CAM use. Among them 720 respondents had agreed to participate in the survey.

\subsection{Measures}

2.3.1. CAM Use. In this study, the following 30 types of CAM modalities were included to define CAM use: acupuncture, moxibustion and cupping, Ayurveda, homeopathic treatment, ginseng, herbs (except ginseng), other natural products (probiotics, enzyme, etc.), diet-based therapies, vitamin and mineral supplements, aroma therapy, folk remedies (animal extracts, etc.), massage and acupressure, spinal manipulation (chiropractic or osteopathic manipulation), Chuna (manipulative therapy practiced in Korean traditional medicine), pilates, yoga, meditation, tai chi, Kouksundo (Korean mindbody practice), art therapy, hypnosis, progressive relaxation, guided imagery, qi gong, prayer therapy, magnetic therapy, light therapy, taping therapy, therapeutic spa in hot springs, and hand acupuncture.

Our list of CAM modalities was partially based on the US National Health Interview Survey [1, 18-20] and was further augmented with a list of modalities from a previous study of CAM use in Korea [18]. This enabled us to include the modalities commonly used in South Korea, which may not be common in other parts of the world.

Participants were asked for their lifetime experience with CAM use and what CAM modality they used. Respondents who have ever used any of 30 modalities of CAM were defined as CAM users. Respondents who used none of the 30 modalities of CAM were considered as non-CAM users. User's satisfaction with CAM was also assessed. Satisfaction levels of each CAM therapy were measured by a 5-point Likert scale (1=very dissatisfied; $2=$ =omewhat dissatisfied; $3=$ neutral; $4=$ somewhat satisfied; $5=$ very satisfied) $[21,22]$.

2.3.2. Factors Associated with CAM Use. The variables, which were used to examine the factors associated with CAM use, included sociodemographic characteristics, perceived general health status (very good, good, fair, poor, or very poor), and presence of health problem [1-3, 19, 20, 23]. Sociodemographic characteristics were as follows: age groups (20-29 years or 30-39 years), sex, education (less than high school, high school, or college or higher), marital status (single, married, or others), religious status (none or having a religion), employment status (unemployed or employed) and monthly family income. Income was divided into $<2$ million Korean Won (KRW), 2-4 million KRW (about US\$1800\$3600), 4-6 million KRW, or $\geq 6$ million KRW (\$5400).

Because there were no respondents who answered 'others' to the question of marital status, it was excluded from the data analysis. Only 9 respondents had less than a high school diploma. The education level was recategorized into "high school or less" or "college or higher". Presence of health problem was defined as presence of at least one physical illnesses or mental illness among the following lists: hypertension, hyperlipidemia, heart diseases, stroke, diabetes, stomach disease, renal disease, lung/respiratory diseases, cancer, neck/shoulder pain, headache, back pain, sleep disorder, depression/anxiety/emotional problem, arthritis/rheumatism, osteoporosis, liver disease, and others $[4,14,19,20]$.

2.3.3. Reasons for Exercise and CAM Use. Reasons for CAM use and adverse events experienced with CAM use were asked. In addition, reasons for doing exercise were asked to all respondents.

2.3.4. Perceptions of CAM. The questionnaires related to perceptions of CAM included the perceived benefits of CAM, the weaknesses of CAM, and the CAM information resources. The respondents were asked the following questions: "What do you think about the benefits of CAM?"; "What do you think about the weaknesses of CAM?"; "Where do you get the information about CAM?". The multiple-choice questionnaires were used and the response choices were presented as categories of variables in Table 5.

2.4. Statistical Analysis. Chi-square analyses and unadjusted logistic regression analyses were used to explore the associations of sociodemographic and health-related factors with CAM use. In addition, a multiple logistic regression analysis 
TABLE 1: Demographic characteristics and the prevalence of CAM use in lifetime.

\begin{tabular}{|c|c|c|c|c|}
\hline Variables & Category & $\begin{array}{c}\text { Total } \\
(\mathrm{n}=649)\end{array}$ & $\begin{array}{l}\text { CAM Users } \\
(\mathrm{n}=526)\end{array}$ & $\begin{array}{c}\text { Non-CAM Users } \\
(\mathrm{n}=123)\end{array}$ \\
\hline \multirow[t]{2}{*}{$\overline{\text { Age }}$} & $20-29$ years & $358(55.2)$ & $280(53.2)$ & $78(63.4)$ \\
\hline & 30-39 years & $291(44.8)$ & $246(46.8)$ & $45(36.6)$ \\
\hline \multirow[t]{2}{*}{ Sex } & Male & $289(44.5)$ & $224(42.6)$ & $65(52.8)$ \\
\hline & Female & $360(55.5)$ & $302(57.4)$ & $58(47.2)$ \\
\hline \multirow[t]{2}{*}{ Marital status } & Single & $572(88.1)$ & 457 (86.9) & $115(93.5)$ \\
\hline & Married & 77 (11.9) & $69(13.1)$ & $8(6.5)$ \\
\hline \multirow[t]{2}{*}{ Education } & High school or less & $166(25.6)$ & $120(22.8)$ & $46(37.4)$ \\
\hline & College or higher & $483(74.4)$ & $406(77.2)$ & $77(62.6)$ \\
\hline \multirow[t]{2}{*}{ Religious status } & None & $441(68.0)$ & $345(65.6)$ & $96(78.0)$ \\
\hline & Have a religion & $208(32.0)$ & $181(34.4)$ & $27(22.0)$ \\
\hline \multirow{3}{*}{ Employment status } & Unemployed & $150(23.1)$ & $113(21.5)$ & $37(30.1)$ \\
\hline & Employed & 499 (76.9) & $413(78.5)$ & $86(69.9)$ \\
\hline & $<2$ million $\mathrm{KRW}$ & $134(20.6)$ & $107(20.3)$ & $27(22.0)$ \\
\hline \multirow{4}{*}{ Monthly family income } & 2-4 million KRW & $325(50.1)$ & $267(50.8)$ & $58(47.1)$ \\
\hline & 4-6 million KRW & $122(18.8)$ & $99(18.8)$ & $23(18.7)$ \\
\hline & $\geq 6$ million $\mathrm{KRW}$ & $68(10.5)$ & $53(10.1)$ & $15(12.2)$ \\
\hline & Very poor/poor & $96(14.8)$ & $85(16.2)$ & $11(8.9)$ \\
\hline \multirow[t]{2}{*}{ Self-perceived health status } & Fair & $254(39.1)$ & $204(38.8)$ & $50(40.7)$ \\
\hline & Good/very good & $299(46.1)$ & $237(45.0)$ & $62(50.4)$ \\
\hline \multirow{2}{*}{ Presence of health problems } & No & $371(57.2)$ & $277(52.7)$ & $94(76.4)$ \\
\hline & Yes & $278(42.8)$ & $249(47.3)$ & $29(23.6)$ \\
\hline \multicolumn{5}{|l|}{ Ten most common problems* } \\
\hline \multicolumn{2}{|l|}{ Neck/shoulder pain } & $203(31.3)$ & & \\
\hline \multicolumn{2}{|l|}{ Headache } & $72(11.1)$ & & \\
\hline \multicolumn{2}{|l|}{ Back pain } & $69(10.6)$ & & \\
\hline \multicolumn{2}{|l|}{ Sleep disorder } & $52(8.0)$ & & \\
\hline \multicolumn{2}{|l|}{ Stomach disease } & $34(5.2)$ & & \\
\hline \multicolumn{2}{|c|}{ Depression/anxiety/emotional problem } & $27(4.2)$ & & \\
\hline \multicolumn{2}{|l|}{ Arthritis/ rheumatism } & $16(2.5)$ & & \\
\hline \multicolumn{2}{|l|}{ Hypertension } & $16(2.5)$ & & \\
\hline \multicolumn{2}{|l|}{ Hyperlipidemia } & $11(1.7)$ & & \\
\hline \multicolumn{2}{|l|}{ Respiratory disease } & $10(1.5)$ & & \\
\hline \multicolumn{2}{|c|}{ Average number of health problems } & $2.0 \pm 1.2$ & & \\
\hline
\end{tabular}

Data are presented as $\mathrm{n}(\%)$ or mean \pm standard deviation.

${ }^{*}$ Multiple responses; respondents who have diseases and symptoms $(n=278)$.

was performed to identify independent predictors statistically significantly associated with CAM use, while controlling for other variables in the model. Both unadjusted and adjusted Odd ratios (ORs) of CAM use were calculated with 95\% confidence intervals (CIs). Data were analyzed using SPSS version 22.0 (IBM SPSS Inc., Chicago, IL). The level of significance was set at $\alpha=0.05$.

\section{Results}

3.1. Sociodemographic and Health-Related Characteristics. Of 649 respondents, 55\% were aged 20-29 years, 56\% female, $88 \%$ single, $74 \%$ college graduate or higher, $77 \%$ employed, and $68 \%$ not having a religion (Table 1). Overall, $85 \%$ of respondents perceived their health as fair or good. About $43 \%$ of respondents had at least one health problem. Of those with health problem, $31 \%$ had the neck and shoulder pain, $11 \%$ headache, and $11 \%$ back pain (Table 1).

3.2. Prevalence and Predictors of CAM Use. Overall, $81 \%$ of respondents had used at least one of 30 CAM therapies in lifetime (Table 2). As presented in Table 1, users of CAM were significantly more likely to be older compared with nonusers ( $47 \%$ versus $37 \%$ ), female ( $57 \%$ versus $47 \%$ ), married (13\% versus 6.5\%), and employed (79\% versus $70 \%)$. They were significantly more likely to have a higher education ( $77 \%$ versus $63 \%$ ), a religion (34\% versus $22 \%$ ), and health problems (47\% versus $24 \%$ ). Monthly family income and self-perceived health status were not related to CAM use. 
TABLE 2: Type and satisfaction of CAM used in lifetime $(n=649)$.

\begin{tabular}{|c|c|c|}
\hline \multirow{2}{*}{ Categories of CAM used* } & CAM Users* & Satisfaction $^{* *}$ \\
\hline & $\mathrm{N}(\%)$ & Mean \pm SD \\
\hline Acupuncture & $423(65.2)$ & $3.42 \pm 1.09$ \\
\hline Massage & $313(48.2)$ & $4.03 \pm 1.16$ \\
\hline Moxibustion and cupping & $271(41.8)$ & $3.43 \pm 1.09$ \\
\hline Yoga & $240(37.0)$ & $3.63 \pm 1.23$ \\
\hline Diet-based therapies & $193(29.7)$ & $3.37 \pm 1.33$ \\
\hline Pilates & $166(25.6)$ & $3.57 \pm 1.36$ \\
\hline Natural products (Ginseng) & $156(24.0)$ & $3.41 \pm 1.12$ \\
\hline Taping therapy & $132(20.3)$ & $3.64 \pm 1.27$ \\
\hline Aroma therapy & 77 (11.9) & $3.81 \pm 1.29$ \\
\hline Natural products (Others) & $72(11.1)$ & $3.56 \pm 1.12$ \\
\hline Spinal manipulation & $71(10.9)$ & $3.66 \pm 1.45$ \\
\hline Meditation & $55(8.5)$ & $3.11 \pm 1.34$ \\
\hline Natural products (Herbs) & $50(7.7)$ & $3.02 \pm 1.38$ \\
\hline Chuna (Korean manipulative therapy) & $49(7.6)$ & $3.67 \pm 1.48$ \\
\hline Hand acupuncture & $43(6.6)$ & $2.98 \pm 1.35$ \\
\hline Vitamin and mineral supplements & $34(5.2)$ & $3.09 \pm 1.53$ \\
\hline Folk medicine (Animal extracts, etc.) & $27(4.2)$ & $2.67 \pm 1.75$ \\
\hline Art therapy & $20(3.1)$ & $3.30 \pm 1.84$ \\
\hline Light therapy & $18(2.8)$ & $2.94 \pm 1.83$ \\
\hline Therapeutic spa in hot springs & $17(2.6)$ & $2.94 \pm 1.85$ \\
\hline Tai chi & $14(2.2)$ & $1.79 \pm 1.93$ \\
\hline Therapeutic prayer & $13(2.0)$ & $2.00 \pm 2.08$ \\
\hline Hypnosis & $12(1.8)$ & $1.67 \pm 1.88$ \\
\hline Ayurveda & $11(1.7)$ & $1.45 \pm 1.70$ \\
\hline Homeopathic treatment & $11(1.7)$ & $2.09 \pm 2.07$ \\
\hline Progressive relaxation & $10(1.5)$ & $2.30 \pm 2.11$ \\
\hline Kouksundo (Korean mind-body practice) & $8(1.2)$ & $1.25 \pm 1.75$ \\
\hline Magnetic therapy & $8(1.2)$ & $1.13 \pm 1.64$ \\
\hline Guided imagery & $6(0.9)$ & $1.33 \pm 2.07$ \\
\hline Qi gong & $3(0.5)$ & $1.67 \pm 2.89$ \\
\hline Any CAM use in lifetime & $526(81.0)$ & \\
\hline \multicolumn{3}{|l|}{ Number of CAM therapies used } \\
\hline $1-3$ & $220(41.8)$ & \\
\hline $4-6$ & $182(34.6)$ & \\
\hline$\geq 7$ & $124(23.6)$ & \\
\hline Average number of therapies used & $4.8 \pm 3.5$ & \\
\hline
\end{tabular}

Data are presented as $\mathrm{n}(\%)$ or mean \pm standard deviation (SD).

* Multiple responses; ten most commonly used CAM therapies are marked in bold.

${ }^{* *}$ Ten most satisfied CAM therapies are marked in bold.

Findings of unadjusted logistic regression analysis (Table 3) were similar to those of chi-square analyses.

Results of multiple logistic regression analysis (Table 3) revealed 3 significant independent predictors of CAM use. Higher education (adjusted OR, 1.76; 95\% CI, 1.11-2.77), having a religion (adjusted OR, 1.75; 95\% CI, 1.08-2.83), and presence of health problem (adjusted OR, 2.79; 95\% CI, 1.72-4.54) were significantly associated with CAM use after controlling for age, sex, marital status, employment status, income, and self-perceived health status.
3.3. Use of CAM Modalities and Satisfaction with CAM. The 10 modalities reported as most frequently used were acupuncture; massage; moxibustion/cupping; yoga; dietbased therapies; pilates; ginseng; taping therapy; aroma therapy; and other natural products (Table 2). The most satisfied therapy with CAM users was massage, followed by aroma therapy, Chuna, spinal manipulation, taping therapy, yoga, pilates, other natural products, moxibustion and cupping, and acupuncture (Table 2). Among CAM users, $41.8 \%$ used 1-3 different CAM therapies; $34.6 \%$ used $4-6$ therapies; $23.6 \%$ 
TABle 3: Predictors of CAM use in lifetime $(n=649)$.

\begin{tabular}{|c|c|c|c|c|c|}
\hline Variables & Category & $\begin{array}{c}\text { Unadjusted OR* } \\
(95 \% \mathrm{CI}) \\
\end{array}$ & $\begin{array}{c}P \\
\text { value } \\
\end{array}$ & $\begin{array}{c}\text { Adjusted } \mathrm{OR}^{*} \\
(95 \% \mathrm{CI}) \\
\end{array}$ & $\begin{array}{c}P \\
\text { value }\end{array}$ \\
\hline \multirow{2}{*}{ Age } & $20-29$ years & Reference & & Reference & \\
\hline & $30-39$ years & $1.52(1.02-2.28)$ & 0.042 & $1.11(0.70-1.77)$ & 0.649 \\
\hline \multirow{2}{*}{ Sex } & Male & Reference & & Reference & \\
\hline & Female & $1.51(1.02-2.24)$ & 0.040 & $1.42(0.94-2.17)$ & 0.099 \\
\hline \multirow{2}{*}{ Marital status } & Single & Reference & & Reference & \\
\hline & Married & $2.17(1.02-4.64)$ & 0.046 & $2.05(0.93-4.56)$ & 0.077 \\
\hline \multirow{2}{*}{ Education } & High school or less & Reference & & Reference & \\
\hline & College or higher & $2.02(1.33-3.07)$ & 0.001 & $1.76(1.11-2.77)$ & 0.015 \\
\hline \multirow{2}{*}{ Religious status } & None & Reference & & Reference & \\
\hline & Having a religion & $1.87(1.17-2.97)$ & 0.008 & $1.75(1.08-2.83)$ & 0.022 \\
\hline \multirow{2}{*}{ Employment status } & Unemployed & Reference & & Reference & \\
\hline & Employed & $1.57(1.02-2.44)$ & 0.043 & $1.46(0.88-2.43)$ & 0.142 \\
\hline \multirow{4}{*}{ Monthly family income } & $<2$ million $\mathrm{KRW}$ & Reference & & Reference & \\
\hline & 2-4 million KRW & $1.16(0.70-1.93)$ & 0.564 & $1.00(0.57-1.73)$ & 0.990 \\
\hline & 4-6 million KRW & $1.09(0.58-2.02)$ & 0.794 & $0.90(0.46-1.75)$ & 0.756 \\
\hline & $\geq 6$ million $\mathrm{KRW}$ & $0.89(0.44-1.82)$ & 0.752 & $0.96(0.46-2.04)$ & 0.921 \\
\hline \multirow{2}{*}{ Presence of health problems } & No & Reference & & Reference & \\
\hline & Yes & $2.91(1.86-4.57)$ & 0.000 & $2.79(1.72-4.54)$ & 0.000 \\
\hline \multirow{3}{*}{ Self-perceived health status } & Very good/good & Reference & & Reference & \\
\hline & Fair & $1.07(0.70-1.62)$ & 0.759 & $0.88(0.56-1.37)$ & 0.565 \\
\hline & Poor/very poor & $2.02(1.02-4.02)$ & 0.045 & $1.31(0.62-2.75)$ & 0.475 \\
\hline
\end{tabular}

*Significant odds ratios (ORs) are marked in bold; CI, confidence interval.

used 7 or more therapies. The average number of therapies used was $4.8 \pm 3.5$.

3.4. Reasons for CAM Use and Exercise. The most frequently reported reason for CAM use was for neck and shoulder pain $(32.5 \%)$, followed by back pain (12.2\%), chronic fatigue $(7.7 \%)$, stress management $(7.7 \%)$, arthritis $(5.7 \%)$, disease prevention and health promotion (5.1\%), and obesity management (4.6\%) (Table 4). Only 3 persons among 271 respondents reported to experience adverse events with CAM therapies. Reasons for doing exercise were "weight loss" $(62.9 \%)$, "health promotion" (53.8\%), "to have a positive body image" (44.8\%), "stress management" (25.1\%), "leisure activity" (18.6\%), "relief of pain" (8.6\%), "treatment of disease" $(4.3 \%)$, and "others" $(0.8 \%)$.

3.5. Perceptions of CAM. The benefit and weakness of CAM and the CAM information resources are presented in Table 5. About $58 \%$ of respondents perceived "relief of pain and symptoms" as the benefit of CAM. Other perceived benefits were "psychological and emotional wellbeing" (40.1\%), "promotion of health and physical fitness" (33.1\%), "improvement of immune function" (12.2\%), and "treatment of disease" (11.1\%). Respondents reported "lack of advertising" (32.2\%), "lack of trust in practitioner" (23.7\%), "nonscientific" (23.0\%), and "expensive cost" (21.1\%) as the weaknesses of CAM.

The information about CAM was gained mainly from the mass media including print and broadcast media (40.1\%), internet (37.6\%), and family and friends (35.3\%). Other CAM information resources that they reported were Western medicine hospitals (7.1\%), Korean traditional medicine hospitals (6.6\%), CAM practitioners (4.6\%), and education including public lectures (3.9\%).

\section{Discussion}

In this study, most common health condition in Korean young adults was musculoskeletal pain including neck, shoulder, and back pain. Korean young adults used CAM mainly to treat these musculoskeletal pains while they did exercise mainly to lose weight, promote health, and have a positive body image. Other reasons for CAM use were "chronic fatigue", "stress management", and "disease prevention and health promotion".

Previous studies about CAM use in university students in the US, India, and the UK reported the similar results that reasons for CAM use were maintenance of physical and mental fitness [7], stress, maintenance of health, and nutrition [6]. Our results also indicate that compared to Korean older adults, Korean young adults presumably have different reasons for CAM use: A previous study reported that the most common reason for CAM use was "lack of energy" followed by "disease prevention" in Korean older adults (3069 years) [18]. Nonetheless, our results were largely consistent with other adult studies as previous studies about CAM use among the general population in all over the world and the US reported that pain-related conditions including back and 
TABle 4: Reasons for CAM use and doing exercise $(n=649)$.

\begin{tabular}{|c|c|c|}
\hline Variables & $\mathrm{N}$ & $\%$ \\
\hline \multicolumn{3}{|l|}{ Top ten reasons for CAM use* } \\
\hline Neck/shoulder pain & 211 & 32.5 \\
\hline Back pain & 79 & 12.2 \\
\hline Chronic fatigue & 50 & 7.7 \\
\hline Stress management & 50 & 7.7 \\
\hline Arthritis & 37 & 5.7 \\
\hline Disease prevention and health promotion & 33 & 5.1 \\
\hline Obesity management & 30 & 4.6 \\
\hline Headache & 25 & 3.9 \\
\hline Stomach disease & 16 & 2.5 \\
\hline Insomnia & 11 & 1.7 \\
\hline \multicolumn{3}{|l|}{ Reasons for exercise ${ }^{* *}$} \\
\hline Weight loss & 408 & 62.9 \\
\hline Health promotion & 349 & 53.8 \\
\hline To have a positive body image & 291 & 44.8 \\
\hline Stress management & 163 & 25.1 \\
\hline Leisure activity & 121 & 18.6 \\
\hline Relief of pain & 56 & 8.6 \\
\hline Disease treatment & 28 & 4.3 \\
\hline Others & 5 & 0.8 \\
\hline
\end{tabular}

${ }^{*}$ Multiple responses; average number of choices was $2.1 \pm 1.2$.

${ }^{* *}$ Multiple responses; average number of choices was $2.2 \pm 1.1$.

TABLE 5: Perceived benefits and weakness of CAM and sources of CAM information.

\begin{tabular}{|c|c|c|}
\hline Variables & $\mathrm{N}$ & $\%$ \\
\hline \multicolumn{3}{|l|}{ Benefits of CAM $(\mathrm{N}=647)^{*}$} \\
\hline Relief of pain and symptoms & 376 & 57.9 \\
\hline Psychological and emotional wellbeing & 260 & 40.1 \\
\hline Promotion of health and physical fitness & 215 & 33.1 \\
\hline Improvement of immune function & 79 & 12.2 \\
\hline Treatment of disease & 72 & 11.1 \\
\hline \multicolumn{3}{|l|}{ Weaknesses of CAM $(\mathrm{N}=649)$} \\
\hline Lack of advertising & 209 & 32.2 \\
\hline Lack of trust in practitioner & 154 & 23.7 \\
\hline Non-scientific & 149 & 23.0 \\
\hline Expensive cost & 137 & 21.1 \\
\hline \multicolumn{3}{|l|}{ Sources of CAM information $(\mathrm{N}=649)^{* *}$} \\
\hline Mass media including print and broadcast media & 260 & 40.1 \\
\hline Internet & 244 & 37.6 \\
\hline Family and friends & 229 & 35.3 \\
\hline Western medicine hospitals & 46 & 7.1 \\
\hline Korean traditional medicine hospitals & 43 & 6.6 \\
\hline CAM practitioners & 30 & 4.6 \\
\hline Education including public lectures & 25 & 3.9 \\
\hline Others & 42 & 6.5 \\
\hline
\end{tabular}

${ }^{*}$ Multiple responses; average number of choices was $1.5 \pm 0.8$.

${ }^{* *}$ Multiple responses; average number of choices was $1.4 \pm 0.7$. 
neck pain were the common health problems associated with CAM use $[1,19,20]$.

The extent of belief in outcomes of health behavior seems to be related to commitment to behavior change: Beliefs in the importance of taking regular exercise for health maintenance were high in young adults and associated with exercise participation [15]. In this study, Korean young adults primarily perceived "relief of pain and symptoms" as the benefit of CAM and thus it seems that the perception of Korean young adults might be reflected in the reason for CAM use.

Exercise has been known to be effective for ameliorating symptoms and risks for diseases including obesity, cardiovascular disease, some cancers, diabetes, osteoporosis, anxiety, and depression $[14,24]$. Accordingly, participation of exercise has been recommended to promote health and maintain a healthy weight [14]. Importantly, motives for participation in exercise are known to be influenced by age $[25,26]$. Consistent with our results, previous studies reported that reasons for exercise in young adults in Europe, the US, and Australia were the management of weight and health and appearance while the important motive in older adults was health benefits [15, 25-28].

According to a previous survey in South Korea, visiting rate of Korean traditional medicine doctors increased between 2008 and 2011 from $45.8 \%$ to $69.3 \%$ of the respondents and the majority of visitors received the acupuncture treatment and moxibustion and cupping therapies [29]. Similarly, our results also showed that acupuncture was most frequently used therapy in young adults followed by massage, moxibustion and cupping therapies, and yoga. Meanwhile, according to the findings of previous studies, CAM treatments frequently used among university students in the US, India, and the UK were dietary supplements including vitamin and herbs, yoga, massage, meditation, and deep breathing exercises [6-8]. Previous studies about CAM use in the general adult population also showed that dietary supplements and herbs were the most frequently used CAM therapy throughout the world including South Korea (followed by Korean traditional medicine), Japan, Malaysia, the EU, and the US [3, 18, 30-32].

Our results regarding factors related to CAM use in young adults were consistent with the findings of previous studies: Sociodemographic factors such as sex (women), older age, higher income, higher level of education $[1,3]$, and poor health status $[19,33]$ were known to be as predictors of CAM use in older adults in all over the world, the US, and Europe. In the present study, higher prevalence of CAM use was observed in women compared to men and in 30-39 years of age group compared to 20-29 years of age group. Users had a higher level of education and were married and employed. Individuals who had any religion were more likely to use CAM than those without religion. In addition, young adults were more likely to use CAM when they had health problems. However, only education level, religious status, and presence of health problems were the independent factors associated with CAM use after controlling for other covariates.

This study has possible shortcomings including limitations of generalizability. The survey was conducted among
Korean young adult members of fitness centers in order to compare the reasons for CAM use to those for exercise, but the study population may not accurately represent the general Korean young adult population. Nevertheless, Korean young adults may be unique and interesting for the study of the patterns and perceptions of CAM use compared with Korean older adults and those in Japan, China, and Western countries. First, in South Korea, unlike Japan and Western countries, a dual licensing system of medical doctors exists: a license for Western medical doctors and the other license for Korean traditional medicine doctors [29, 34]. Second, the government supports to promote Korean traditional medicine research since 2008 may have a considerable influence on the improvement in attitudes toward Korean traditional medicine in South Korean society [29]. These changes in attitude toward Korean traditional medicine and unique medical system of South Korea could influence on the patterns of CAM use in Korean young adults.

In conclusion, this study suggested that the main purposes of CAM and exercise are different in young adults in South Korea: They did exercise mainly to lose weight, to promote health, and to have a positive body image while they used CAM mainly to relieve musculoskeletal pains. Our results also showed that use of CAM was significantly associated with education level, religious status, and health status in young adult users of fitness centers. Notably, majority of respondents answered that they got CAM information from the mass media and the internet instead of CAM officials including Korean traditional medicine doctors and CAM practitioners, suggesting that official efforts to confirm the adequacy of the information may be needed to enhance the use of CAM in young generation. In the future, a comparison study among the same generations in different countries will be needed to fully understand patterns, reasons, and perspectives of exercise and CAM use in diverse cultural, social, and economic backgrounds.

\section{Data Availability}

The data used to support the findings of this study are available from the corresponding author upon request.

\section{Disclosure}

Seung-Nam Kim and Bokmin Kim are co-first authors.

\section{Conflicts of Interest}

The authors declare that they have no conflicts of interest.

\section{References}

[1] M. Frass, R. P. Strassl, H. Friehs, M. Müllner, M. Kundi, and A. D. Kaye, "Use and acceptance of complementary and alternative medicine among the general population and medical personnel: a systematic review," The Ochsner Journal, vol. 12, no. 1, pp. 45$56,2012$.

[2] P. E. Harris, K. L. Cooper, C. Relton, and K. J. Thomas, "Prevalence of complementary and alternative medicine (CAM) use 
by the general population: a systematic review and update," International Journal of Clinical Practice, vol. 66, no. 10, pp. 924939, 2012.

[3] T. C. Clarke, L. I. Black, B. J. Stussman, P. M. Barnes, and R. L. Nahin, "Trends in the use of complementary health approaches among adults: United States, 2002-2012," National Health Statistics Reports, vol. 10, no. 79, pp. 1-16, 2015.

[4] J. A. Astin, K. R. Pelletier, A. Marie, and W. L. Haskell, "Complementary and alternative medicine use among elderly persons: one- year analysis of a blue shield Medicare supplement," The Journals of Gerontology. Series A, Biological Sciences and Medical Sciences, vol. 55, no. 1, pp. M4-M9, 2000.

[5] C. K. Cheung, J. F. Wyman, and L. L. Halcon, "Use of complementary and alternative therapies in community-dwelling older adults," The Journal of Alternative and Complementary Medicine, vol. 13, no. 9, pp. 997-1006, 2007.

[6] J. Nguyen, M. A. Liu, R. J. Patel, K. Tahara, and A. L. Nguyen, "Use and interest in complementary and alternative medicine among college students seeking healthcare at a university campus student health center," Complementary Therapies in Clinical Practice, vol. 24, pp. 103-108, 2016.

[7] K. Subramanian and I. Midha, "Prevalence and perspectives of complementary and alternative medicine among university students in Atlanta, Newcastle upon Tyne, and New Delhi," International Scholarly Research Notices, vol. 2016, Article ID 9309534, 9 pages, 2016.

[8] A. L. Versnik Nowak, J. Degise, A. Daugherty et al., "Prevalence and predictors of complementary and alternative medicine (CAM) use among ivy league college students: implications for student health services," Journal of American College Health, vol. 63, no. 6, pp. 362-372, 2015.

[9] P. Gardiner, K. J. Kemper, A. Legedza, and R. S. Phillips, "Factors associated with herb and dietary supplement use by young adults in the United States," BMC Complementary and Alternative Medicine, vol. 7, article 39, 2007.

[10] J. E. Perkin, W. J. Wilson, K. Schuster, J. Rodriguez, and A. AllenChabot, "Prevalence of nonvitamin, nonmineral supplement usage among university students," Journal of American Dietetic Association, vol. 102, no. 3, pp. 412-414, 2002.

[11] T. Lee, "The integration of Korean medicine in South Korea," Acupuncture in Medicine, vol. 33, no. 2, pp. 96-97, 2015.

[12] R. Chou, A. Qaseem, V. Snow et al., "Clinical efficacy assessment subcommittee of the American College of Physicians; American College of Physicians; American Pain Society low back pain guidelines panel. Diagnosis and treatment of low back pain: a joint clinical practice guideline from the American College of Physicians and the American Pain Society," Annals of Internal Medicine, vol. 147, no. 7, pp. 478-491, 2007.

[13] A. D. Furlan, F. Yazdi, A. Tsertsvadze et al., "A systematic review and meta-analysis of efficacy, cost-effectiveness, and safety of selected complementary and alternative medicine for neck and low-back pain," Evidence-Based Complementary and Alternative Medicine, vol. 2012, Article ID 953139, 61 pages, 2012.

[14] W. L. Haskell, I.-M. Lee, R. R. Pate et al., "Physical activity and public health: updated recommendation for adults from the American College of Sports Medicine and the American Heart Association," Circulation, vol. 116, no. 9, pp. 1081-1093, 2007.

[15] A. Steptoe, J. Wardle, R. Fuller et al., "Leisure-time physical exercise: Prevalence, attitudinal correlates, and behavioral correlates among young Europeans from 21 countries," Preventive Medicine, vol. 26, no. 6, pp. 845-854, 1997.
[16] A. E. Ready, B. J. Naimark, R. Tate, and S. L. Boreskie, "Fitness centre membership is related to healthy behaviours," The Journal of Sports Medicine and Physical Fitness, vol. 45, no. 2, pp. 199207, 2005.

[17] E. C. Schroeder, G. J. Welk, W. D. Franke, D. Lee, and C. P. Earnest, "Associations of health club membership with physical activity and cardiovascular health," PLoS ONE, vol. 12, no. 1, Article ID e0170471, 2017.

[18] S. M. Ock, J. Y. Choi, Y. S. Cha et al., “The use of complementary and alternative medicine in a general population in South Korea: results from a national survey in 2006," Journal of Korean Medical Science, vol. 24, no. 1, pp. 1-6, 2009.

[19] J. A. Astin, "Why patients use alternative medicine: results of a national study," Journal of the American Medical Association, vol. 279, no. 19, pp. 1548-1553, 1998.

[20] P. M. Barnes, B. Bloom, and R. L. Nahin, "Complementary and alternative medicine use among adults and children: United States, 2007," National Health Statistics Reports, vol. 10, no. 12, pp. 1-23, 2009.

[21] R. B. Bourne, B. M. Chesworth, A. M. Davis, N. N. Mahomed, and K. D. J. Charron, "Patient satisfaction after total knee arthroplasty: who is satisfied and who is not?" Clinical Orthopaedics and Related Research, vol. 468, no. 1, pp. 57-63, 2010.

[22] P. Tucker and J. D. Irwin, “University students' satisfaction with, interest in improving, and receptivity to attending programs aimed at health and well-being," Health Promotion and Practice, vol. 12, no. 3, pp. 388-395, 2011.

[23] OECD, "Perceived health status," in Health at a Glance 2017, pp. 62-64, OECD Indicators, OECD Publishing, Paris, France, 2017.

[24] Y. K. Kesaniemi, E. Danforth, M. D. Jensen, P. G. Kopelman, P. Lefebvre, and B. A. Reeder, "Dose-response issues concerning physical activity and health: an evidence-based symposium," Medicine \& Science in Sports \& Exercise, vol. 33, no. 6, pp. S351S358, 2001.

[25] K. M. Trujillo, R. R. Brougham, and D. A. Walsh, "Age differences in reasons for exercising," Current Psychology, vol. 22, no. 4, pp. 348-367, 2004.

[26] J. C. Quindry, D. Yount, H. O’Bryant, and M. E. Rudisill, “Exercise engagement is differentially motivated by age-dependent factors," American Journal of Health Behavior, vol. 35, no. 3, pp. 334-345, 2011.

[27] M. Kilpatrick, E. Hebert, and J. Bartholomew, "College students' motivation for physical activity: differentiating men's and women's motives for sport participation and exercise," Journal of American College Health, vol. 54, no. 2, pp. 87-94, 2005.

[28] G. S. Kolt, R. P. Driver, and L. C. Giles, "Why older Australians participate in exercise and sport," Journal of Aging and Physical Activity, vol. 12, no. 2, pp. 185-198, 2004.

[29] J.-M. Woo, E.-J. Park, M. Lee, M. Ahn, S. Kwon, and K. H. Koo, "Changes in attitudes toward and patterns in traditional Korean medicine among the general population in South Korea: a comparison between 2008 and 2011," BMC Complementary and Alternative Medicine, vol. 14, article 436, 2014.

[30] S. Eardley, F. L. Bishop, P. Prescott et al., "A systematic literature review of complementary and alternative medicine prevalence in EU," Forschende Komplementärmedizin, vol. 19, supplement 2, pp. 18-28, 2012.

[31] Z. M. Siti, A. Tahir, A. I. Farah et al., "Use of traditional and complementary medicine in Malaysia: a baseline study," Complementary Therapies in Medicine, vol. 17, no. 5-6, pp. 292299, 2009. 
[32] H. Yamashita, H. Tsukayama, and C. Sugishita, "Popularity of complementary and alternative medicine in Japan: a telephone survey," Complementary Therapies in Medicine, vol.10, no. 2, pp. 84-93, 2002.

[33] L. M. Kemppainen, T. T. Kemppainen, J. A. Reippainen, S. T. Salmenniemi, and P. H. Vuolanto, "Use of complementary and alternative medicine in Europe: health-related and sociodemographic determinants," Scandinavian Journal of Public Health, vol. 46, no. 4, pp. 448-455, 2018.

[34] N. Ishizaki, T. Yano, and K. Kawakita, "Public status and prevalence of acupuncture in Japan," Evidence-Based Complementary and Alternative Medicine, vol. 7, no. 4, pp. 493-500, 2010. 


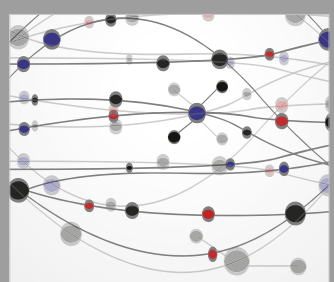

The Scientific World Journal
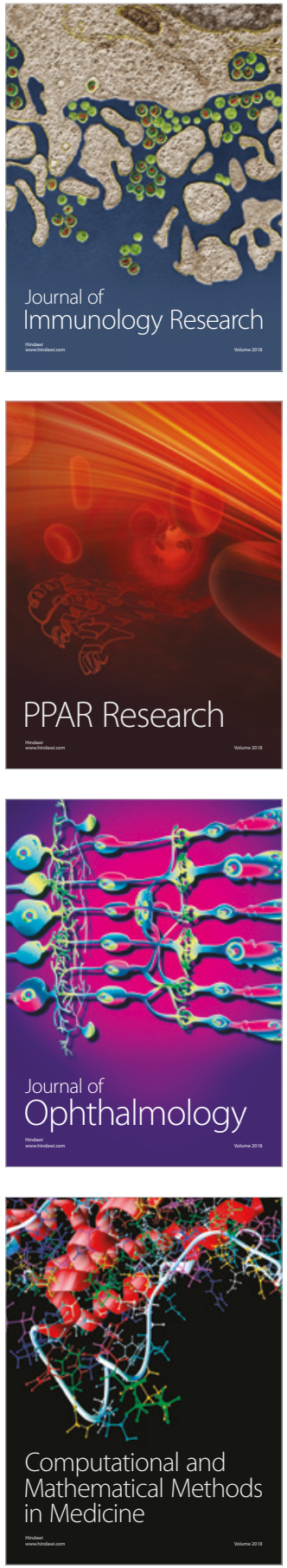

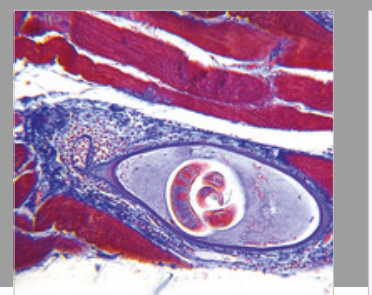

Gastroenterology Research and Practice

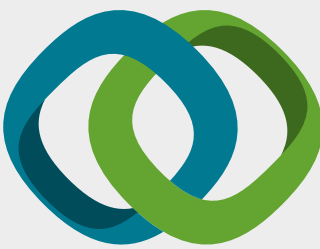

\section{Hindawi}

Submit your manuscripts at

www.hindawi.com
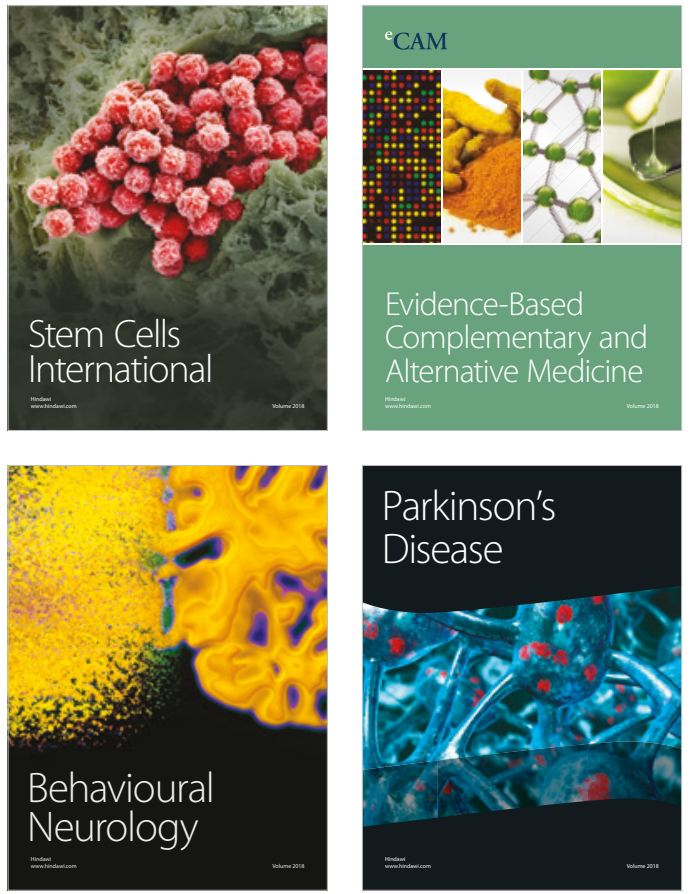

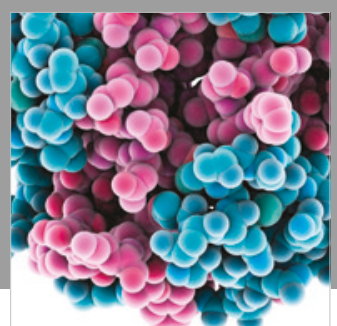

ournal of

Diabetes Research

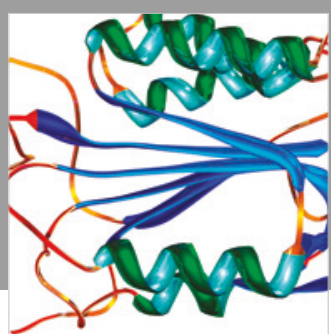

Disease Markers
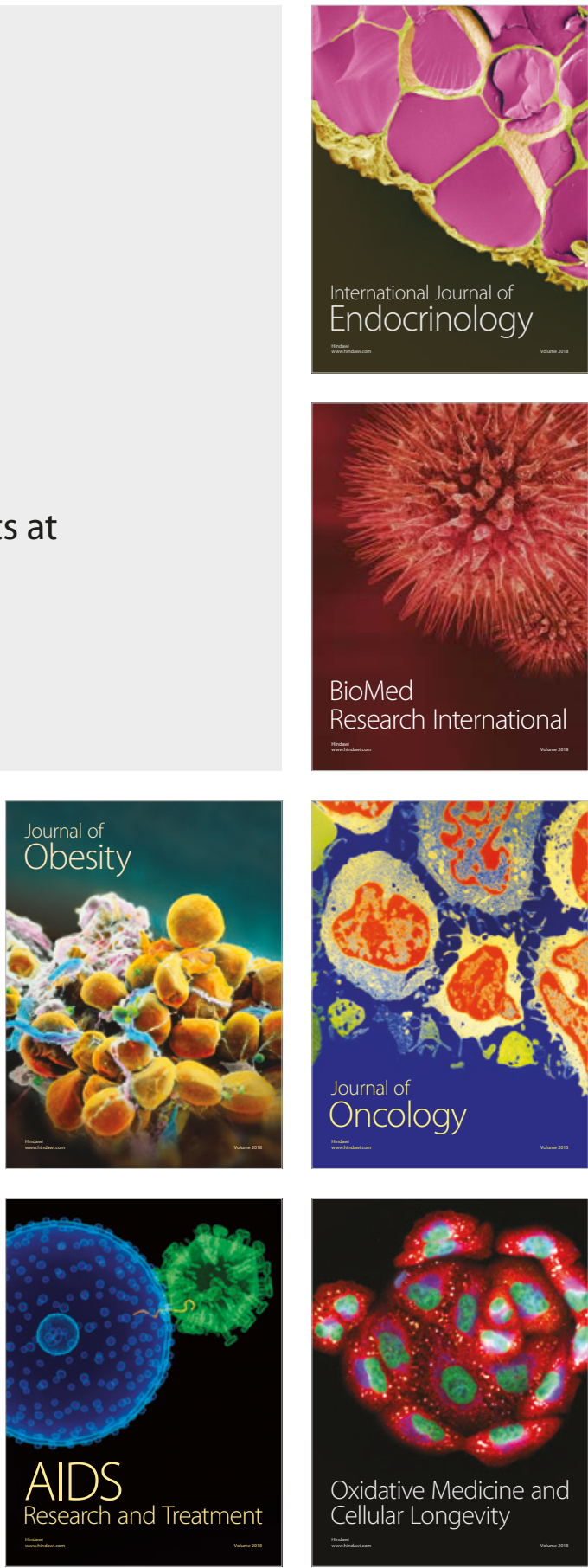